\title{
Celso Furtado, intérprete do Brasil
}

\author{
[Celso Furtado, interpreter of Brazil
}

\section{Alexandre de Freitas Barbosa ${ }^{\mathrm{I}}$}

Agradeço aos pareceristas pelos valiosos comentários sobre o texto.

RESUMO $O$ presente artigo procura discutir a originalidade da interpretação do Brasil contida em Formação econômica do Brasil, obra clássica de Celso Furtado. Para tanto, são recuperadas as matrizes formadoras do seu pensamento no sentido de mostrar como são operacionalizadas por meio do seu método histórico-estrutural. O plano da obra, o método e o estilo permitem entrosar passado, presente e futuro de modo inovador, trazendo novas possibilidades de compreensão e transformação do Brasil. Finalmente, o artigo estabelece um diálogo com as interpretações predecessoras de Gilberto Freyre, Sérgio Buarque de Holanda e Caio Prado Jr. • PALAVRAS-CHAVE - Subdesenvolvimento; método histórico-estrutural; desenvolvimento nacional; pensamento econômico; intérpretes do Brasil. · ABSTRACT - This article seeks to discuss the originality of the interpretation of Brazil undertaken in the book "Formação econômica do Brasil”, Furtado's masterpiece. In order to do so, it highlights the main tenets of his thought, which paved the way for Furtado's historical-structuralist method. The structure of the book, its method and style allowed the interplay of different spaces and times in such an innovative way that opened new potential avenues for understanding and changing the Brazilian reality of his time. At last, it establishes a dialogue between this interpretation of Brazil and the ones launched by his predecessors: Gilberto Freyre, Sérgio Buarque de Holanda and Caio Prado Jr. • KEYWORDS · Underdevelopment; Latin American structuralism; national development; economic thought; interpretations of Brazil.

Recebido em Iํ de setembro de 2020

Aprovado em II de dezembro de 2020

BARBOSA, Alexandre de Freitas. Celso Furtado, intérprete do Brasil. Revista do Instituto de Estudos Brasileiros, Brasil, n. 78, p. 86-I07, abr. 202I.

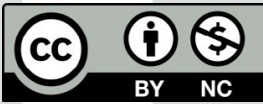

DOI: https://doi.org/Io.II6o6/issn.23I6-90IX.vIi78p86-I07

I Universidade de São Paulo (USP, São Paulo, SP, Brasil). 
Há várias formas de abordar o pensamento de Celso Furtado. Pode-se focar na sua contribuição no campo da economia. Na maestria com que aprumou o método histórico-estrutural para escrutinar o movimento da história brasileira na longa duração. Na maneira como logrou injetar racionalidade na esfera política apostando no aprofundamento da democracia. Ou como processou as "influências" de vários autores das ciências sociais para moldar uma interpretação original. E como articulou a economia a outras dimensões da vida brasileira - a cultura, a política e a sociedade -, sem praticar o imperialismo econômico. Pode-se ainda ressaltar a trajetória do intelectual e de como ela se faz sentir na sua produção, de tal modo que a obra e o intelectual aparecem fundidos ao processo histórico.

O desafio de escrever sobre o Celso Furtado, intérprete do Brasil, é que esta escolha impõe de saída uma fusão das possibilidades acima esboçadas. É mais e menos do que fazer tudo isso somado. Menos, porque cada perspectiva exige um artigo em si. E mais, porque não se pode abrir mão de nenhuma dessas veredas, sob pena de perder de vista a totalidade do seu pensamento, que forja uma interpretação original sobre o Brasil.

Levando em consideração essas peculiaridades do Furtado intelectual, para dar conta da sua intepretação do Brasil, seguimos o seguinte percurso analítico. Em primeiro lugar, apresentamos as matrizes formadoras do pensamento furtadiano, as quais atuam como ferramentas para a construção do método histórico-estrutural, tal como aplicado em Formação econômica do Brasil, como procuramos elucidar na segunda parte do artigo. Portanto, este texto se dedica a esse livro, que dá início a um conjunto de interpretações sobre o Brasil de sua lavra, que vêm em seguida nos anos I960 e I970, e sobre as quais não nos detemos, com a exceção de Desenvolvimento e subdesenvolvimento e A pré-revolução brasileira, que comungam do mesmo horizonte analítico e de expectativa da sua obra magna.

$\mathrm{Na}$ terceira parte do artigo, realizamos um diálogo de Furtado com as interpretações clássicas do Brasil que lhe antecederam. O objetivo é explicitar, como e por que Furtado se inscreve no panteão dos "demiurgos do Brasil contemporâneo" segundo a denominação de Francisco de Oliveira (I997, p. I9). O artigo conta ainda com uma breve reflexão sobre a atualidade do pensamento de Furtado nas suas "Considerações finais". 


\section{AS MATRIZES FORMADORAS DO PENSAMENTO FURTADIANO}

Se Celso Furtado, como típico sertanejo, não gostava de falar sobre si, escreveu muito sobre a sua obra, talvez por reescrevê-la continuamente. Livro após livro, ele se refazia, incorporando novas hipóteses e conceitos e abandonando antigas formulações. Podemos encontrar algumas pistas do seu percurso nos vários depoimentos sobre a própria trajetória (obra autobiográfica) ou nos diários recentemente publicados.

Nos textos autobiográficos, em lugar do anedótico, predomina a parcimônia do escritor marcado por uma atitude republicana extremada. A sua participação é relatada como se estivesse o servidor público a prestar contas dos seus atos à nação, ou então movido pelo zelo de contar a história em que jogou papel de relevo e, apenas por isso, se sente na obrigação de colocá-la no papel.

Em alguns momentos, Furtado se detém sobre os autores que marcaram o seu pensamento. Em artigo publicado em I973, ele aponta as "três correntes principais" que desde cedo deram sentido à sua trajetória intelectual, e de forma persistente, pois "se entrelaçaram" nos anos subsequentes à sua formação universitária (FURTADO, [I973] 2013, p. 39-4I).

Em primeiro lugar, o positivismo, com a defesa da primazia da razão e do conhecimento científico como fonte do progresso. A segunda influência encontra-se em Marx, pela ênfase na historicidade das formas sociais, aprofundada com a leitura de Mannheim, que, mesmo não sendo marxista, encara o conhecimento como produtor de história. Rompe-se assim a oposição entre conhecimento científico e ideológico. A terceira corrente está associada à antropologia cultural dos Estados Unidos, via Gilberto Freyre, especialmente pelo instrumental metodológico de conceber os fenômenos, não em si, mas na sua interação cultural.

Mais adiante, no mesmo texto, Furtado ([I973] 20I3, p. 45) menciona os autores da escola histórica alemã, Max Weber, Georg Simmel e Werner Sombart, além da "importância definitiva" de Henri Pirenne. No caso de Weber, tudo indica que a obra do sociólogo alemão deva ser imputada como uma quarta corrente pela importância que assume em vários dos seus escritos a distinção entre "racionalidade dos meios" e "racionalidades dos fins". Os valores devem condicionar os meios, conforme a sua menção explícita a Weber em entrevista a Lourdes Sola (I998, p. I52)2.

No nosso entender, a importância de Weber na sua obra se faz sentir também na construção de tipos ideais, instrumento utilizado de forma recorrente na investigação histórica furtadiana. Com uma particularidade, os tipos ideais são construídos a partir da experiência histórica sintetizada nos seus elementos "estruturais" e não a partir de um esforço de sistematização "em estado puro", que apenas depois deve passar pelo crivo da história.

É importante lembrar que o jovem Furtado lera, nas traduções do Fondo de Cultura Económica, Economia e sociedade, de Weber, e O capital, de Marx, já no ano de I946 (D’AGUIAR, 20I4, p. 22). A metodologia weberiana para descrever o processo histórico de maneira sintética parece se aproveitar de um eixo diacrônico marxista

2 Na entrevista, Furtado (apud SOLA, I998, p. I52) diferencia os "tecnocratas", que vieram depois do golpe de I964, dos "técnicos em fins" do segundo governo Vargas. 
que incorpora "a análise das estruturas sociais" como uma chave "para compreender o comportamento das variáveis econômicas" (FURTADO, [I967] I987, p. 84)3.

Sobre Henri Pirenne, vale lembrar a influência exercida por esse historiador sobre Fernand Braudel e a École des Annales. A título de ilustração, Braudel ficara "boquiaberto", na sua juventude, com a sua capacidade de estabelecer "interações entre macroeconomia, história política e civilização” (DAIX, I999, p. I08-I09)4.

No pós-Segunda Guerra Mundial, Furtado navega nas mesmas águas que os historiadores franceses: se estes buscavam auxílio nas ciências sociais, o jovem pesquisador seguia o mesmo caminho em sentido inverso (FURTADO, [I987] 20I3b, p. 53). O método comparativo histórico lhe permite saltar "os limites da história nacional” para alcançar "uma visão de conjunto" (SILVA, 20II, p. I75-I8I), conectando o espaço nas suas distintas temporalidades. Em registro no seu diário, durante o doutorado na Sorbonne, ele se ressente do método histórico tradicional, "fundado numa imensa erudição", para completar: "falta o ar novo da pesquisa sociológica" (FURTADO, 20I9, p. 92-93).

Nesse sentido, Furtado teve a "sorte" de se escorar em Pirenne, que lhe preparou o terreno para o acesso à nova corrente da historiografia francesa. Auxiliado pelo historiador belga, Furtado se apropria, por meio da história, e à sua maneira, dos instrumentos metodológicos provenientes tanto de Marx como de Weber, como das categorias keynesianas ao longo de sua obra. Pirenne está presente na tese de doutorado de I948 como também no importante exercício de "teoria da história" contido em Desenvolvimento e subdesenvolvimento (FURTADO, [I96I] I965), mais especificamente no capítulo 3.

Na tese de doutorado, defendida em I948, Furtado se aproveita da noção de feudalismo como espaço centrado no mundo rural, onde predomina a atrofia da divisão do trabalho, para marcar a presença do comércio como fator desagregador das relações de produção no campo na esteira da expansão urbana. Na terceira parte da tese, ele se apoia mais uma vez em Pirenne para destacar "a correlação entre os períodos da história social do capitalismo com a formação de novas elites dirigentes" (FURTADO, [I948] 200I, p. 20; p. I46).

Portanto, Pirenne lhe permite demarcar a transição entre sistemas econômicos (MALLORQUIN, 2005, p. 6I-63), a "economia comercial" e a "economia industrial": a primeira, capaz de estabilizar-se secularmente; e a segunda, "condenada a crescer ou decrescer", pois se retiver os lucros reduz a renda de outros grupos à maneira keynesiana (FURTADO, [I96I] I965, p. I52-I53). Mas também lhe é útil para explicitar a diferença entre os "rentistas ociosos" do açúcar colonial e a "vanguarda de homens

3 Nessa obra, apesar de discordar do Marx do "determinismo econômico", que parte de "uma posição filosófica em face da história” (FURTADO, [I967] I987, p. I3; 34-35), Furtado ([I967] I987, p. I3; 34-35) ressalta a raiz marxista na interação entre os fatores econômicos e não econômicos, característica do "estruturalismo latino-americano".

4 Segundo Daix (I999, p. I08), Henri Pirenne era uma "espécie de divindade tutelar" à qual recorriam Lucien Febvre e Marc Bloch, os criadores da Revue des Annales.

5 Anotação de 2I de março de 1947 dos seus diários. 
com experiência comercial" que presidem a gestação da econômica cafeeira no século XIX (FURTADO, [I959] I989, p. II4-II5) em Formação econômica do Brasil.

Surgem assim os tipos ideais (Weber) não apenas em escala global, mas também em escala territorial e ao longo do tempo no Brasil, viabilizando a contraposição entre a "economia cafeeira" periférica e a "economia industrial" do centro (FURTADO, [I959] I989, p. I58-I59). Na longa duração de Formação econômica do Brasil, as elites dirigentes se sucedem no espaço e no tempo, gerando várias formas de circulação e distribuição da renda (Keynes), além de estruturas sociais correlatas (Marx), muitas das quais se "ossificam" e travam a transformação do sistema.

As correntes principais do pensamento de Celso Furtado - positivismo, antropologia cultural norte-americana, Marx (via Mannheim), às quais adicionamos a metodologia weberiana e a sociologia histórica dos sistemas econômicos de Pirenne - serão operacionalizadas à sua maneira. Elas fornecem a embocadura metodológica para assimilar os autores com os quais ele se defronta quando se transforma em importante economista da Comissão Econômica para a América Latina (Cepal) nos anos I950.

Esse processo é tudo menos natural e apenas possível de ser destrinchado por meio de sua obra a partir de I959. Procuramos mapear essas influências a partir da sua obra, sem cair na "ilusão biográfica", o que ocorreria se simplesmente "aceitássemos" as referências por ele consideradas como decisivas para a sua trajetória intelectual.

Até Formação econômica do Brasil, Furtado passa por um processo de "experimentação teórica", repleto de ambivalências, refletindo a ausência de uma "unidade discursiva", pois o autor sofre uma "tensão constante" entre as categorias vigentes da economia convencional e a tentativa de aproximação das realidades históricas concretas (MALLORQUIN, 2005, p. 49-50).

O núcleo de autores economistas é conformado por Keynes, Schumpeter, Perroux, Myrdal e Prebisch, assimilados a partir dos trilhos metodológicos traçados acima. Furtado ([I980] 2000, cap. 3) refere-se a esses economistas como aqueles que exerceram "influência sobre a nova visão do desenvolvimento" formulada pela geração de estruturalistas latino-americanos. O resultado da combustão, no seu caso específico, é uma forma de pensar a economia enraizada na história e no espaço, e que avança em conjunto com as estruturas sociais.

Esses autores mencionados ao final de sua trajetória intelectual são processados não em sua totalidade, mas conforme os aspectos filtrados por Furtado a partir do seu esforço metodológico original. Eles lhe fornecem o instrumental analítico a embasar a sua interpretação sobre as estruturas em transformação do desenvolvimento e do subdesenvolvimento no final dos anos I950, e que mais adiante, dão lugar a "uma visão global do capitalismo" (FURTADO [I980] 2000, p. 29).

Furtado, ao indicar a importância desses autores economistas, ressalta o resultado da travessia e não o percurso realizado. Ainda assim, podemos dizer que a fusão das suas categorias e perspectivas o auxiliou na sua compreensão peculiar dos processos econômicos.

Vejamos o fio condutor que une esses pensadores econômicos. Conforme a sua avaliação, "Keynes restabeleceu a primazia do político sobre o econômico", "ao conceber a política econômica como um esforço coordenado de decisões" (FURTADO 
[I980] 2000, p. 3I). Recupera as alavancas do Estado como agente econômico estratégico, bem como o papel da demanda efetiva e o papel do investimento na sua composição. Para então completar: "Ora, se a luta contra o desemprego requeria uma ação diretora do Estado sobre o conjunto do sistema econômico, que dizer das transformações estruturais sem as quais dificilmente se poderia escapar ao subdesenvolvimento?" (FURTADO [I980] 2000, p. 3I). Deixa subentendido que o pensador econômico da periferia deve ser pós-keynesiano na veia.

Quanto a Schumpeter, herda mais o papel do empresário inovador a detonar transformações nas estruturas produtivas, com "óbvias afinidades com a visão dialética da história que serviu de fundamento à sociologia econômica de Marx" (FURTADO [I980] 2000, p. 32). As mudanças estruturais, concebidas como processos irreversíveis, abrem novas possibilidades às forças sociais. É então que Furtado ([I980] 2000, p. 33) se pergunta: no século XX, é possível conceber o empresário schumpeteriano na periferia "substituído por uma vontade política a serviço da reconstrução social”?

Já François Perroux relaciona as macrodecisões econômicas que agem sobre o espaço, criando novas formas de dominação e de estratificação social que não se irradiam de forma espontânea. De Myrdal, ele empresta o papel desequilibrador do processo de acumulação. Longe de ser linear, o desenvolvimento é caracterizado como uma "causação circular e cumulativa”, onde o fator impulsionador das mudanças gera uma cadeia de reações, sem perspectiva de estabilização (FURTADO [I980] 2000, p. 33-35).

Raúl Prebisch, cujo objetivo inicial era demonstrar como se dava a propagação internacional do ciclo de negócios, termina por investigar a dualidade intrínseca do sistema global capitalista. Deslocando a análise do alto nível de abstração da teoria das vantagens comparativas, observa os processos de formação de preços de forma casada às estruturas sociais. $\mathrm{O}$ foco é a concentração do progresso técnico e do excedente nos países do centro (FURTADO [I980] 2000, p. 37-38).

Para Furtado, Prebisch representa o exemplo de que é possível avançar no plano da teoria, cuja falsidade muitas vezes reside na incorreta identificação objetiva dos problemas. A “capacidade de generalizar" deve andar de mãos dadas com a "capacidade de explicar", o que exige a ampliação dos quadros da construção teórica", abrindo espaço para a inclusão de "mais e mais casos especiais" (FURTADO, [I96I] I965, p. I05-I07).

Essas matrizes do seu pensamento apenas podem ser condensadas porque, em sua concepção, o conhecimento resulta de uma atividade criadora e deve servir como suporte para a ação. Duas posturas fundamentais caracterizam a trajetória intelectual de Furtado (I998, p. IO-II): o "compromisso ético com os valores universais", atuando ao lado das "forças sociais cujos interesses se confundem com os da coletividade nacional"; e a natureza do trabalho do pesquisador, movido pela "imaginação e coragem para arriscar na busca do incerto", mesmo que tenha que se enfrentar com a "ciência institucionalizada".

A sua participação na Cepal durante oito anos (I949-I957) coloca Furtado no centro do debate econômico sobre desenvolvimento em escala internacional. A reflexão sobre o Brasil se nutre dessa posição de técnico das Nações Unidas, que circula pelo mundo, e debate com as principais referências no campo do pensamento econômico, 
ao mesmo tempo em que forja um repertório de conceitos e um método que apenas se explicitam em Formação econômica do Brasil.

A originalidade da sua interpretação está no fato de que nenhuma das matrizes do seu pensamento aparece em sua integralidade na sua obra. Elas se transfiguram lapidadas pelo seu método construído para destrinchar o seu objeto de análise. Não se trata de armar mais uma "teoria” a ser "testada”, mas de dissecar com as suas próprias ferramentas, como um cientista travestido de cirurgião, a "formação histórica de uma estrutura subdesenvolvida específica” (BIELSCHOWSKY, I995, p. I66).

\section{FORMAÇÃo ECONÔMICA DO BRASIL: MÉTODO, ESTRUTURA E ESTILO}

Na sua juventude, com I8 anos recém-completados, Furtado redige no seu diário uma anotação sobre uma "ideia que há tempo venho acariciando". Pretende escrever uma "História da Civilização Brasileira", assim em maiúsculas como a registrar a dimensão da empreitada. Em tom de profunda autoconfiança, o jovem esclarece que "seria uma obra completa sob o ponto de vista crítico-filosófico", pois "não seguiria o plano até hoje seguido pelos nossos historiadores". Isso porque "ao lado das influências individuais observaria as influências das coletividades". Para arrematar: "não me deixaria emaranhar pelos fatos" (FURTADO, 20I9, p. 48)6.

Ao final de sua vida, mais sóbrio, os ombros vergados pelo peso do tempo e das tantas batalhas, talvez olhasse com certa ironia para o jovem do passado. Não obstante, Furtado começa a palestra proferida na Faculdade de Administração, Economia e Contabilidade da Universidade de São Paulo (FEA/USP), em I998, com a seguinte afirmação: "pensar o Brasil foi o desafio que sempre guiou minha reflexão" (FURTADO, I999, p. 69).

Exatos 60 anos haviam se passado entre a anotação do adolescente ambicioso e o depoimento do intelectual renomado. Escrever Formação econômica do Brasil foi a forma encontrada para fazer da pedra o seu caminho.

O livro foi escrito em Cambridge, na Inglaterra, entre novembro de I957 e fevereiro de I958, "nas 'sobras de tempo' que ia furtando ao festival do debate teórico", conforme relata o seu autor. O “festival” contava com a presença de alguns dos principais economistas do momento, dentre eles Nicholas Kaldor, Piero Sraffa, Joan Robinson e Amartya Sen, os "keynesianos de esquerda" do departamento de economia da universidade (FURTADO, I985, p. 202; p. 204).

$\mathrm{Na}$ sua temporada em Cambridge, o economista pretendera dedicar-se essencialmente ao trabalho teórico. Mas o mergulho na compreensão da realidade brasileira era uma espécie de ajuste de contas consigo mesmo. No seu primeiro livro autobiográfico, Furtado fala sobre o método: "aproximar a História (visão global) da análise econômica". A economia daria conta de formular "perguntas precisas", para "obter respostas da História” (FURTADO, I985, p. 204-205).

Para não ficar "num alto nível de abstração", optou por pintar um "afresco" com "segmentos estruturados" (as cinco partes do livro), que carregariam uma "coleção

6 Anotação de 20 de agosto de I938, escrita em Recife. 
de hipóteses com demonstrações apenas iniciadas ou sugeridas", estimulando outros pesquisadores a aprofundarem a investigação. A "omissão dos detalhes historiográficos" justificava-se "para que o leitor captasse facilmente o movimento no tempo do conjunto observado" (FURTADO, I985, p. 205).

O prefácio do livro procura explicitar o seu objetivo. Para Furtado, o livro "pretende ser tão somente um esboço do processo histórico de formação da economia brasileira”. Por isso, destina-se a "um público mais amplo", com ênfase "nos estudantes de ciências sociais, das faculdades de economia e filosofia em particular". Em seguida, o autor afirma não se deter sobre "a bibliografia histórica brasileira", pois o seu objetivo "é simplesmente a análise dos processos econômicos e não a reconstituição dos eventos históricos que estão por trás desses processos" (FURTADO, [I959] I989, "Introdução").

Não se tratava de obra de história econômica e nem de economia stricto sensu. Tampouco se propunha a fazer um debate com as interpretações históricas existentes. O livro de Roberto Simonsen, História econômica do Brasil, foi utilizado mais como fonte de dados. Os demais livros citados foram, em grande medida, consultados na Biblioteca de Cambridge.

Segundo o historiador Ruggiero Romano ([I970] 2009, p. 434), Furtado buscou "reconstruir por sua própria conta toda uma série de mecanismos capazes de conduzir a uma compreensão melhor dos problemas do presente”. Conforme a síntese de Francisco de Oliveira (2003, p. 84), "o andamento se faz tecendo os fios de uma construção autoestruturante, em que a história é teoria e a teoria é história”.

É importante destacar que o método histórico-estrutural chega à sua maturidade a partir de Furtado e com Formação econômica do Brasil. Tal método estava apenas implícito na Cepal, cujas análises possuíam o objetivo principal de elaborar prescrições de política embasadas na compreensão da especificidade latino-americana. A longa duração da história, no sentido braudeliano, ainda não havia sido decodificada. O próprio artigo em que Braudel (I992) procura formalizar o seu enfoque metodológico é de 19587.

Nesse sentido, Formação econômica do Brasil é um livro braudeliano avant la lettre ${ }^{8}$, com uma diferença importante: ele parte do pressuposto de que as transformações estruturais em curso na sociedade brasileira (a "conjuntura), desde que empurradas por políticas e reformas no plano dos "acontecimentos", poderiam romper com a "história lenta", ou seja, com os traços ainda remanescentes do passivo colonial.

Em colóquio realizado em Paris, no ano de I97I, Furtado descreve de maneira sucinta o método que orienta a escrita e a composição de Formação econômica do Brasil. No seu entender, toda vez que um economista se depara com um "conjunto social complexo", ele o faz - ou apenas pode fazê-lo, é o que sugere - por meio de "uma visão global fornecida pela história”. Do contrário, tem-se apenas uma "sintaxe" desprovida de significado e, portanto, incapaz de ação política transformadora. Isso

7 O artigo "História e as ciências sociais: a longa duração" é publicado na Revue des Annales no número de outubro-dezembro de 1958 .

8 Temos em mente aqui menos a obra de Braudel sobre o Mediterrâneo e mais a sua trilogia sobre o capitalismo, quando o historiador analisa de forma entrosada as várias temporalidades da história no contexto de diferentes espaços e de suas vinculações às suas respectivas economias-mundo. 
porque "inexiste análise macroeconômica sem uma globalização histórica prévia" (FURTADO, I97I, p. 23-24 - tradução nossa).

Por outro lado, para cada um dos "cortes sincrônicos" operados, apenas as ferramentas da economia ou das ciências sociais dão conta de fornecer um "quadro analítico" de modo a iluminar o jogo intricado de potencialidades e resistências, responsável por fazer escoar a história (FURTADO, I97I, p. 24-tradução nossa). Desde que o analista saiba perceber, com objetividade e imaginação criativa, as interações entre as estruturas e as instituições, entre o econômico e o não econômico, entre as rupturas e as continuidades que dão sentido ao processo histórico.

Vale ressaltar que em Formação econômica do Brasil, o método é “aplicado", mas sem que se faça menção a ele, a não ser na introdução, quando despretensiosamente se refere à dinâmica histórica que está por trás dos processos econômicos, ou quando sugere que a economia faça perguntas à história, processo invertido na obra, pois a história também inquire a economia. Na síntese de Frédéric Mauro ([I972] 2009, p. 447), Furtado concebeu "uma dinâmica econômica retrospectiva nutrida de história e nutrindo-a bem".

O livro Desenvolvimento e subdesenvolvimento, coletânea de artigos publicada em I96I, nos fornece pistas sobre o método histórico-estrutural utilizado em Formação econômica do Brasil. No capítulo 4, Furtado se detém sobre as "estruturas subdesenvolvidas". No seu entender, elas não são "uma etapa pela qual tenham, necessariamente, passado" as economias desenvolvidas. Essas diferenças estruturais - ao contrário do "raciocínio por analogia" do tipo "aqui" como "lá" tão em voga no momento em que escreve - precisam ser compreendidas, exigindo um "esforço teórico autônomo” (FURTADO, [I96I] I965, p. I7I-I73; p. I85). Para fazê-lo, ele adota o raciocínio por contraste.

Ora, o capítulo 4 de Desenvolvimento e subdesenvolvimento foi escrito depois de Formação econômica do Brasil. Tudo indica que o aprofundamento da "teoria do subdesenvolvimento" tenha sido informado pelo mergulho na história a partir de um método concebido com esse intuito. E que o método não estivesse "pronto" antes de Formação econômica do Brasil. Talvez seja o caso de supor que ele o lapidou ao longo da escrita, enquanto apurava o estilo.

Furtado já escrevera sobre a economia colonial no seu doutorado de I948. No livro A economia Brasileira, de I954, o autor empreendera a análise da economia cafeeira, que recebe a cunhagem de "nova economia colonial", além de apresentar os elementos que explicam o "deslocamento do centro dinâmico", responsável por detonar o processo de industrialização pós-I930 (FURTADO, I954).

A terminologia ainda está em processo de elaboração em I954. A "nova economia colonial" conta com "trabalho assalariado", e a crise de I929 aponta para uma "economia de mercado interno", em tudo diferente da "economia colonial" típica, "exportadora-escravocrata". Esses três "cortes verticais" circunscrevem-se, em grande medida, à operação das variáveis econômicas, sendo precedidos e sucedidos por capítulos que mais complicam a vida do leitor.

Os capítulos I e 6 de A economia Brasileira, de natureza teórica, não dialogam com as três fases da economia ("sistemas econômicos brasileiros"), que, por sua vez, se ressentem da falta de enraizamento no espaço - não há nem o "complexo 
econômico nordestino" e tampouco as Minas Gerais do século XVIII com seus "nexos de solidariedade econômica" -, na história e nas forças políticas de conservação e transformação, como Furtado desenvolve com primazia no livro publicado cinco anos adiante. $\mathrm{O}$ autor também tem "menos" história atrás de si. O prefácio é concluído em outubro de I953, em um momento de indefinição do governo Vargas e quando ainda não se sabe que Juscelino Kubitschek (JK) está por vir. A história encontra-se marcada por uma nebulosa de possibilidades.

Mas a principal "sacada" já surge de maneira embrionária: a tentativa de que "nos colocássemos em distintas posições no tempo, e das mesmas tentássemos um corte vertical no processo histórico" (FURTADO, I954, p. I4-I5). No entanto, os "modelos" construídos a partir dos fluxos da renda aparecem sem os agentes sociais, dificultando a elucidação das limitações e potencialidades do contexto local (nos seus vários espaços e temporalidades) e internacional. Os centros de decisão aparecem mais como resultantes do que como geradores das operações de política econômica.

Portanto, algumas das vigas aparecem antes de a maquete ter sido completada. É um livro mais de economista cepalino do que furtadiano se partirmos do pressuposto de que esse adjetivo apenas passa a fazer sentido depois da sua obra-prima. Nessa, não há capítulo teórico, pois a teoria serve de suporte ao método que descortina o processo histórico por meio de balizas estruturais.

Método, estruturação do plano do livro e estilo fizeram a diferença em Formação econômica do Brasil. Por meio de novas categorias longamente sopesadas, e fazendo uso de uma espécie de vaivém permanente entre impossibilidades do passado, incompletudes do presente e potencialidades do futuro, o livro é uma espécie de romance histórico. Depois de se deter em cada corte sincrônico, ele avança diacronicamente, quando surgem então velhos e novos personagens reposicionados pela trama. Romance da coletividade nacional antes da sua consciência do subdesenvolvimento, inclusive antes que existisse coletividade nacional, como se depreende da obra, pois a estrutura econômica e social da colônia não engendrara centros de decisão internos.

Nessa obra, Furtado fisga o essencial (o geral e o particular) da empresa colonizadora na primeira parte, para depois detalhar a diferença entre a "Economia escravista de agricultura tropical" (parte 2) e a "Economia escravista mineira" (parte 3). Até então tivéramos um crescimento extensivo sem alterações estruturais. A parte 4, "Economia de transição para o trabalho assalariado", recebe os quatro novos capítulos sobre "O problema da mão de obra", que não estavam em A economia brasileira, além da discussão sobre a Independência e a estrutura de poder na Primeira República, que emprestam novo sentido à mutação observada durante a segunda metade do século XIX e o seu impacto sobre as "desigualdades regionais".

No capítulo 18, aparece, de maneira sintética, o personagem central do drama, "o confronto com o desenvolvimento dos Estados Unidos”. Padrão de desenvolvimento, estrutura social, papel do Estado e hábitos de pensamento conformam um todo que explica "por que se industrializaram os EUA no século XIX, emparelhando-se com as nações europeias, enquanto o Brasil evoluía no sentido de transformar-se no século 
XX numa vasta região subdesenvolvida" (FURTADO, [I959] I989, p. I00)9. Furtado responde a essa questão recorrendo à história - encarada não como uma fatalidade por meio de uma investigação da complexa interação entre as estruturas econômicas e sociais e os centros de decisão.

Aqui os personagens históricos Alexander Hamilton e Visconde de Cairu - tal como tencionara o adolescente na anotação de 1938 - surgem imbrincados a um processo de longa duração, cada qual empunhando a sua leitura de Adam Smith (FURTADO, [I959] I989, p. IOI), que encontra respaldo na estrutura social mais ampla. Sem alarde, a sociologia da cultura dá o ar da sua graça num livro de "história econômica".

Essa veia é retomada adiante, no capítulo 27, quando Furtado analisa as dificuldades do funcionamento do padrão ouro nas "economias dependentes". O recurso à desvalorização da moeda - a chamada "inconversibilidade" - aparece quase como uma imposição do "novo sistema", agora funcionando à base de "trabalho assalariado" no centro dinâmico embrionário da periferia. Mas o "homem público brasileiro" - cujos conhecimentos de economia ingressam pelas faculdades de direito da época - tende a "raciocinar por analogia" com o que ocorria na Europa. A "inconversibilidade" é vista como algo "patológico" (FURTADO, [I959] I989, p. I60). Se o "mimetismo das elites" da época impede a compreensão do funcionamento do real, nem por isso deixa de atuar como o seu lastro subjetivo.

Finalmente, na parte 5, "Economia de transição para um sistema industrial”, o autor revela como a crise de I929, com a desvalorização cambial, "eliminava um dos instrumentos mais efetivos de defesa da velha estrutura econômica com raízes na era colonial" (FURTADO, [I959] I989, p. 203). Ao descrever o processo de industrialização por substituição de importações, o autor apresenta o seu diagnóstico. Se acena para as virtualidades, que dependem da emergência de novos centros de decisão, enuncia todos os dilemas advindos do processo (capítulos 34 a 36) - inflação, desequilíbrio externo, disparidades regionais e sociais, concentração fundiária -, os quais impõem limites estruturais à afirmação de um projeto nacional de desenvolvimento.

A mensagem é a seguinte: apenas a compreensão da dinâmica do subdesenvolvimento, agora descortinada analítica e historicamente, pode dar sentido a esse projeto, que deve contar com o apoio de vastos segmentos sociais. Do contrário, a "antiprofecia" (BARBOSA, 20Io, p. I47) com que termina o livro se consumará: "sendo assim, o Brasil por essa época [final do século XX] ainda figurará como uma das grandes áreas da terra em que maior é a disparidade entre o grau de desenvolvimento e a constelação de recursos potenciais" (FURTADO, [I959] I989, p. 242).

No documentário de José Mariani (2004), O longo amanhecer: cinebiografia de Celso Furtado, o economista fornece um depoimento sobre Formação econômica do Brasil. Afirma que não se preocupara em preparar um desfecho para o livro. Do contrário, teria que dizer que "as fases se sucedem e todas elas levam à mesma coisa”, à concentração

9 Em anotação de dezembro de I989 nos seus diários, depois de regressar de viagem aos Estados Unidos, Furtado faz "uma digressão sobre Formação econômica do Brasil", indicando como a incursão no estudo da formação desse país serviu como "recurso" para "melhor entender as anomalias inerentes ao nosso subdesenvolvimento" (FURTADO, 20I9, p. 4I2-4I3). 
da renda, embora sob formas distintas. Em vez de abrir o horizonte de oportunidades, a obra ficaria presa ao curto prazo. Uma leitura cuidadosa do último capítulo, "Perspectivas dos próximos decênios", permite comprovar a afirmação do autor.

Por sua vez, o parágrafo que contém a "antiprofecia" é uma espécie de convite ao leitor para ingressar junto com o autor no palco da história e se somar à batalha para a superação do subdesenvolvimento. O processo de transformação das estruturas, que o livro acompanha desde a colônia, agora transcorre à sua frente. Com objetividade e parcimônia - combinação que leva à "polidez discursiva", "sem tom querelante ou confrontações pessoais" a que se refere Luiz Felipe de Alencastro (2009, p. 32) -, o autor cativa os leitores com uma narrativa que ensina economia e o seu jargão técnico para mostrar que o mais importante está além, ou seja, na possibilidade de autotransformação nacional.

Dentre os ávidos leitores de Formação econômica do Brasil, encontram-se os quadros do setor público e da sociedade civil em ebulição, além dos jovens estudantes de economia e ciências sociais. Buscam compreender os dilemas da nação, para além do bordão do governo JK. Querem explicações que desçam além da superfície marcada pela euforia.

Portanto, ao elucidar o processo histórico, com foco na economia, mas sem perder de vista as dimensões social, política e cultural, e fazendo cirúrgicos cortes transversais no tempo e no espaço, de modo a indicar como essas dimensões se articulam nos planos interno e externo - pois o seu objetivo era chegar ao presente, para influenciar o futuro -, com Formação econômica do Brasil, Furtado incorpora-se de maneira decisiva à história do país.

Não apenas porque passa a ser reconhecido como o seu autor, mas principalmente porque a leitura da sua obra - direta ou indiretamente, já que muitos a leem por meio dos relatos de outrem-passa a fazer parte do repertório essencial não somente dos intelectuais, mas dos agentes políticos e sociais. A interpretação que Furtado oferece em Formação econômica do Brasil vem impregnada de projeto e de utopia, aos quais ele dá continuidade nas atividades que exerce e que passam a ser do conhecimento da sociedade.

Quem era Celso Furtado então? Um dos economistas de maior reputação no Brasil, graças ao período em que atuara como quadro técnico da Cepal. Circula junto aos técnicos do setor público no Brasil, especialmente os encarregados da gestão econômica, ou vinculados a entidades de classe, como a Confederação Nacional da Indústria (CNI), e a instituições como o Instituto Superior de Estudos Brasileiros (Iseb), por exemplo. Mas o técnico - subitamente transformado em intelectual - pouco transitava nas altas esferas políticas.

Antes de sua temporada em Cambridge, Furtado ministra uma série de conferências no Banco Nacional de Desenvolvimento Econômico e Social (BNDE) sob o título Perspectivas da economia brasileira, obra que seria publicada no ano seguinte, em I958, quando retorna ao Brasil. Já cogitava se desligar da Cepal e se despir do "manto protetor e imobilizador de funcionário internacional” (FURTADO, I985, p. 200).

Entre I958 e I964, Celso Furtado ingressa de cheio na cena política nacional. Conhece todos os políticos e representantes da sociedade civil, a quem procura convencer sobre a importância da batalha da Superintendência do Desenvolvimento do Nordeste (Sudene) - sob a sua liderança entre I959 e I964 - e a urgência da execução 
do Plano Trienal (I963), agora como ministro do Planejamento. Transforma-se numa espécie de "intelectual estadista" (BARBOSA, 2020, p. 344). Empurrado para a arena política, procura estabelecer consensos em torno de uma plataforma coerente capaz de integrar desenvolvimento, estabilização e reformas de base. Num contexto de acirramento dos conflitos, procura mantê-los dentro dos limites institucionais por meio de uma agenda democrática que canalize as energias sociais com o duplo propósito de dinamizar a economia e superar as estruturas anacrônicas (CEPÊDA, 200I, p. I80-I82).

Portanto, as coordenadas do seu pensamento desse período podem ser encontradas no seu livro teórico Desenvolvimento e subdesenvolvimento (I96I) e em A pré-revolução brasileira (I962), um panfleto político no melhor sentido do termo. Nesse último, Furtado fornece as diretrizes básicas à nação que ficara devendo no último capítulo de Formação econômica do Brasil (I959).

Formação econômica do Brasil, a história condensada das estruturas na longa duração, deve ser lido em conjunto com seu livro teórico e com a sua utopia, como se compusessem uma trilogia, contendo o método em sua forma mais abstrata, seu desenvolvimento na história e as potencialidades do futuro em face da encruzilhada. No seu panfleto, os dilemas são expostos sem meias-palavras: "abriremos uma nova fase de transformações qualitativas em nossa formação de nação continental, ou caminharemos para uma cristalização da estrutura já estabelecida?” (FURTADO, I962, p. I07).

O impacto imediato de Formação econômica do Brasil, associado ao fato de que aparece em todos os lugares como o homem responsável pela saga da Sudene, faz com que, em julho de I959, ele redija a seguinte anotação em seu diário: "começo a ser uma pessoa notória” (FURTADO, 20I9, p. I73). Pouco antes, em maio do mesmo ano, ele relata um debate que ocorrera em Natal, contando com a participação de bispos e do público em geral. Conforme sua anotação: "abordamos todas as questões e aparentemente as respostas foram convincentes. A sinceridade também é uma forma de demagogia. Se bem utilizada" (FURTADO, 20I9, p. I54). Tal como na sua obra-prima.

O historiador Francisco Iglesias ([I963] (2009), p. 4I6) vai direto ao ponto: "pela primeira vez no Brasil um economista se tornou figura popular, sem que cortejasse a opinião com linguagem política: mantendo sempre o tom do técnico, sem exibicionismo pedante nem tom de quem faz campanha eleitoral". Com um único adendo, o tom do técnico explicitava um projeto, que era político no sentido mais amplo da palavra, e um compromisso social com os despossuídos, por meio de reformas estruturais. Isso fazia dele o oposto do tecnocrata, personagem que emerge na cena brasileira com o golpe de I964 que envia Furtado para o exílio.

\section{FURTADO E AS INTERPRETAÇÕES DO BRASIL}

Procuramos, em seguida, desenvolver que tipo de interpretação do Brasil nos fornece Celso Furtado na sua obra magna, que como sugerimos acima deve ser lida junto com Desenvolvimento e subdesenvolvimento e A pré-revolução brasileira. Para tanto, buscamos estabelecer um diálogo com as interpretações de Gilberto Freyre, Sérgio Buarque de Holanda e Caio Prado Jr. 
Uma primeira diferença marcante reside na sua historicidade. Três autores nos permitem realçar esse aspecto. Para Luiz Felipe de Alencastro (2009, p. 24), diferentemente de Furtado, para os autores que escreveram suas obras clássicas entre I933 e I942, "a irrealização do presente dificultava a incorporação do passado na perspectiva do futuro". Francisco de Oliveira (2003, p. I9) é mais enfático: "enquanto as obras anteriores explicaram e 'construíram' o país do passado [...], a de Furtado era contemporânea da sua própria 'construção”'. O depoimento de Fernando Henrique Cardoso ([I978] 20I3, p. 207-208) também se revela elucidativo: a sua geração, posterior à de Antonio Candido, "também aprendeu com aqueles autores". Para completar: "mas a sua descoberta intelectual fundamental deu-se com a leitura de Celso Furtado": aquilo "foi um choque enorme".

Portanto, no final dos anos I950, existe um processo em curso, dotado de novo sentido, e que potencializa um salto histórico. A compreensão do funcionamento da industrialização problemática e do papel do Estado - agindo em sintonia com um conjunto de forças sociais - coloca o debate num outro patamar.

Em A pré-revolução brasileira, Furtado afirma que os três decênios que vão de I930 a I960 representam "etapa decisiva de desagregação da economia colonial" (FURTADO, I962, p. 64). O grau de diferenciação do sistema produtivo permitiu "transferir para o país os principais centros de decisão de sua vida econômica” (FURTADO, I962, p. 9). Em seguida vem a assertiva: "se no passado não podíamos mais que perscrutar as tendências da economia internacional [...], hoje estamos em condições de tomar as decisões mais fundamentais concernentes à atividade econômica do país”. Para concluir, "o mais importante não é que podemos autodirigir-nos, e sim que não nos não resta outra saída senão fazê-lo” (FURTADO, I962, p. Io).

Os dilemas do subdesenvolvimento, manifestos sob a forma de tensões estruturais, resultam da aceleração do desenvolvimento industrial. O seu prosseguimento exige políticas que permitam dar "maior elasticidade às estruturas" (FURTADO, I962, p. 3I), como no caso da reforma agrária, administrativa, fiscal e bancária. A ação estatal deve estar, por sua vez, subordinada "a uma clara definição de objetivos de desenvolvimento econômico e social” (FURTADO, I962, p. 3I).

O debate com Caio Prado Jr. é evidente, muito embora o diálogo entre os dois intelectuais tenha sido, muitas vezes, investigado por meio de uma espécie de economia política das (não)citações. Furtado citara Caio Prado no seu doutorado - defendido em I948 e publicado em $200 \mathrm{I}$ - mas não em Formação econômica do Brasil. Teria ele subestimado a importância de Caio Prado Jr. na sua obra? Menos mencionado é o fato de que o historiador paulista não cita Formação econômica do Brasil em nenhuma das suas obras escritas depois do lançamento do clássico. A que se deve esse silêncio de ambos os lados?

Parece-nos mais fecundo em termos intelectuais promover o diálogo entre os autores a partir de suas obras. Antes disso, vale lembrar que o uso que Celso Furtado faz de Caio Prado e Gilberto Freyre no seu doutorado é basicamente instrumental. Essas obras aparecem "desfiguradas", pois ele não se detém na sua "organicidade interna”, antes utilizando passagens que são refutadas ou assimiladas. Tal como aponta Roberto Pereira Silva (20II, p. 2I3-222), Furtado se socorre de Caio Prado na crítica a Gilberto Freyre, mostrando como a sociedade patriarcal na colônia se origina 
da monocultura, da grande propriedade e da escravidão. O quadro mais amplo é descortinado a partir de Henri Pirenne e dos historiadores portugueses António Sérgio e João Lúcio de Azevedo. Por exemplo, sobre a questão se "houve feudalismo no Brasil?”, Furtado (200I, p. 79-86) rebate Pedro Calmon e Capistrano de Abreu caiopradianamente, mas a partir das leituras de Henri Pirenne e Werner Sombart.

Tudo indica que a leitura de Caio Prado Jr. não lhe abriu caminhos para desvendar a realidade colonial, partindo antes das referências europeias. Seguiu outro percurso, passando à margem do primeiro ensaio ousado de aplicação do método histórico-estrutural no país, a partir da chave do materialismo histórico. Furtado partiu das matrizes formadoras do seu pensamento, especialmente de Keynes e da Cepal, enraizando as suas formulações na história. Caio Prado, ao contrário, concebeu a totalidade social do Brasil colônia a partir da história, operacionalizada pelo "sentido da colonização" e de como ele era reforçado nas várias dimensões da vida coletiva.

Caio Prado Jr. também indicou como, no século XIX, as transformações internacionais - imperialismo inglês e novas formas de inserção externa - e internas - fim do tráfico e, depois, da escravidão - explicitavam as contradições e as potencialidades da nação, vistas sob o ângulo do mercado interno como forma de superação da colônia. O seu limite, contudo, estava na compreensão de que uma "economia colonial" deveria ser sucedida por uma "economia nacional", concebida de forma vaga e imprecisa como aquela caracterizada pela "organização da produção em função das necessidades próprias da população” (PRADO JR., [I945] I985, p. 270).

Apesar de História econômica do Brasil não ser a sua grande obra em termos metodológicos, pois escrita em I945 para um público estrangeiro e "atualizada" em I970, para Caio Prado, não se gestaram no país "as condições necessárias para um desenvolvimento industrial em larga escala”. Portanto, sequer se pode falar de "industrialização" (PRADO JR., [I945] I985, p. 287-289; p. 299; p. 333). O ciclo que se abre no pós-I930 é mais a "crise de um sistema" do que o início de outro.

O texto de Caio Prado Jr. de I954, escrito para o concurso à cadeira de economia política da Faculdade de Direito da USP, nos permite aprofundar esse diálogo entre os dois intelectuais. Aqui ele se dedica às limitações do processo de industrialização no Brasil. A sua formulação, coerente com os conceitos trabalhados ao longo da sua trajetória, é a seguinte: "o sistema colonial da economia brasileira, dominante em nossos dias" trava a possibilidade de emergência de "um capitalismo propriamente brasileiro", no que diz respeito às nossas relaç̧ões econômicas internas (PRADO JR., I954, p. 82-83).

Cauteloso, Caio Prado contesta a formulação de que se deva "apressar um processo de evolução para o capitalismo", pois nossa história é outra e não se reproduzem processos de desenvolvimento. Mas ressalta que o "desenvolvimento qualitativo" exige uma "reestruturação econômica", impossível senão através da "recomposição do sistema geral em que se processa o desenvolvimento". Portanto, o sistema colonial atua condicionando negativamente o desenvolvimento brasileiro, que assume uma feição apenas quantitativa (PRADO JR., I954, p. 76-79; p. 82-86; p. I53-I57; p. I6I-I66).

Caio Prado Jr., no mesmo texto de I954, critica a Cepal, especialmente Prebisch e os novos teóricos do desenvolvimento, por suas "raízes ideológicas", o que lhes impede "uma apreciação adequada do conjunto e fecunda nos seus resultados práticos para as economias subdesenvolvidas". O ataque mais frontal é dirigido ao "caráter estático" 
das formulações da Cepal, "que não recua suficientemente no tempo, ou lhe faz apenas referências ocasionais e sumárias” (PRADO JR., I954, p. I7-23). Se a primeira afirmação representa um distanciamento em termos teóricos, a segunda deixa de fazer sentido depois de Formação econômica do Brasil.

Furtado dá um salto adiante de Caio Prado ao dissecar o "sentido da industrialização", apontando como se desorganizam as estruturas do "sistema colonial", já a partir da "economia de transição para o trabalho assalariado", por meio da utilização de categorias cepalinas e keynesianas. Mostrando como interagem o centro e a periferia, nos vários períodos históricos, ele molda um universo discursivo em que o político e o ideológico aparecem agora sintetizados em torno do centro de decisão por excelência, o Estado. Abre-se um caminho para superar por meio de reformas os "obstáculos" - que remetem à condição de subdesenvolvimento não apenas herdada do passado, mas redefinida no presente - antepostos à nação.

Isso posto, são várias as conexões metodológicas entre os dois autores, apesar dos marcos teóricos e focos de análise distintos. A própria noção de que a colônia não é o atraso, mas o outro lado do mundo moderno em gestação, "a parte de um todo, incompleta sem a visão deste todo" (PRADO JR., I942, p. I4-I5), pode ser a vista como a primeira incursão do pensamento brasileiro sobre o "subdesenvolvimento", conceito pouco utilizado por Caio Prado. Parece-nos inclusive não haver introdução mais adequada a Formação econômica do Brasil do que a elaborada pelo historiador paulista em I942: "é por isso que para compreender o Brasil contemporâneo precisamos ir tão longe; e subindo até lá, o leitor não estará ocupando-se apenas de devaneios históricos; mas colhendo dados, e dados indispensáveis para interpretar e compreender o meio que o cerca na atualidade" (PRADO JR., I942, p. 6).

A diferença reside no seguinte ponto: escrevendo a partir do espaço de experiência estatal, e munido das novas técnicas e categorias do pensamento econômico assimiladas pelo método histórico-estrutural, Furtado foi capaz de fornecer de quebra um programa coerente de ação para o futuro.

Celso Furtado leu Casa-grande ersenzala (FREYRE, [I933] I973) já no Rio de Janeiro em I940 (D’AGUIAR, 20I4, p. I5). Segundo seus depoimentos, essa obra "corrigiu os excessos de seu historicismo" (FURTADO, I999, p. 9), além de "revelar todo um instrumental novo de trabalho" (FURTADO, [I973] 20I3, p. 4I). Que maior exemplo possível de imaginação criadora do que esse livro do sociólogo pernambucano? Que impacto teria sobre ele a leitura do prefácio à primeira edição, em que Freyre escreve o seguinte trecho: "era como se tudo dependesse de mim e dos de minha geração; de nossa maneira de resolver questões seculares” (FREYRE, [I933] I973, p. lvii)?

A monocultura açucareira aparece em Freyre como uma das vigas da estratificação social, tendo a miscigenação contribuído para atenuar os antagonismos de raça e de classe. Portanto, a economia é o chão a partir do qual se desenvolve a cultura. Mas as tensões sociais, em vez de fazerem mover a história, se dissolvem para ceder lugar a um regime "em vários aspectos, democrático, flexível e plástico" (FREYRE, [I933] I973, p. lviii; p. lx; p. 52-53). Os antagonismos se equilibram, e a cultura aparece como a mediadora universal.

Em Furtado, a operação metodológica é quase a oposta. Ou as formas sociais e culturais resistem mesmo tendo as formas de produção se tornado obsoletas, 
"persistindo" em um contexto de estagnação e travando o desenvolvimento, como no Nordeste (FURTADO, [I948] 200I, p. I48-I49), ou as novas formas econômicas e sociais, engendradas em sintonia com o contexto internacional, propiciam a emergência de novas elites e valores com potencial transformador.

Nesse caso, os centros de decisão impulsionam rupturas na economia, permitindo (ou não) desenvolver as possibilidades estruturais contidas nas novas formas sociais. Pois a disputa, em última instância, se dá na estrutura de poder. A leitura do capítulo 29 de Formação econômica do Brasil revela a ascendência no período republicano dos novos interesses regionais, associados aos interesses agrícola-exportadores, especialmente do setor cafeeiro, mas também a emergência de "grupos sociais de rendas não derivadas da propriedade” (FURTADO, [I959] I989, p. I7I-I73). Essa nova conformação social inaugura um período de tensões, inclusive no plano ideológico, cuja resolução seria encaminhada apenas no período pós-I930, conforme a sua síntese.

Permitimo-nos lançar a seguinte conjectura: não seria o Gilberto Freyre ([I936] I996) de Sobrados e mucambos aquele que permite um diálogo de maior envergadura com Furtado? Nessa obra, o sociólogo pernambucano traça, "em ritmo lento", a decadência do senhor rural, "que não foi imediata", assim como tampouco se mostrou "súbita a ascensão da burguesia". Houve um processo de "reeuropeização das elites" - uma espécie de reconquista pela "Nova Europa" - por meio da "industrialização e urbanização dos estilos da vida brasileira” (FREYRE, [I936] (I996), p. I34-I37). Uma nova "paleotécnica" emergiu na infraestrutura urbana, diminuindo a distância social entre a gente senhorial e as elites inseridas nas atividades comerciais, financeiras e industriais (FREYRE, [I936] (I996), p. 308-344).

O paralelo com o conceito de "modernização", introduzido por Furtado nas suas obras dos anos I970, é sugestivo. Trata-se de uma atualização dos padrões de consumo das elites num quadro de parco desenvolvimento das forças produtivas e marcado pelo "imobilismo social" (FURTADO, [I980] 2000, p. 80-8I). O excedente gerado na periferia é canalizado para os bens e técnicas que compõem o consumo das elites sob forte impacto da "colonização cultural". Se o encaixe é perfeito para o século XIX, o modelo não passa por alterações substantivas a partir de meados do século XX, quando o aparato produtivo sofre uma descontinuidade para reproduzir aqui dentro - via industrialização - os padrões de consumo da minoria modernizada (FURTADO, I974, p. 87-90).

Ressalte-se ainda que o conceito de "modernização" permite a Furtado reconsiderar a tese da virada dos anos I950, de que a industrialização gera a formação de sistemas econômicos nacionais. O raciocínio por contraste cede lugar ao raciocínio dialético, uma vez que as relações centro-periferia se alteram de forma substantiva, o centro penetrando na periferia para se servir dela, aprofundando assim o seu subdesenvolvimento, agora "industrializado". Mas aqui já estamos em outro terreno: o das interpretações do Brasil formuladas pelo economista-cientista social no pós-I964.

E no caso de Sérgio Buarque? Se não há menção explícita de Furtado à influência/ leitura dessa obra, isso não significa que inexistam paralelos. Francisco de Oliveira (2003, p. 66-68; p. 78-79) lança a hipótese de que no tocante ao papel do Estado, central na obra de Furtado, ele "precisa" se escorar nos clássicos autoritários - Oliveira Vianna e Alberto Torres - uma vez que o Estado não está presente nas interpretações dos anos I930. 
Mas o faz por meio de uma assimilação mannheimiana: o planejamento assegura um processo de racionalização democrática a partir do Estado. Portanto, não aparece como força externa a projetar tendências vigentes da formação social sobre o plano político e "por cima". De fato, Furtado não deduz o Estado da sociedade, e nem o contrário, pois estabelece relações entre as duas instâncias, e não apenas no plano da economia.

Por mais que Oliveira (2003, p. 62) admita ser possível encontrar em Raízes do Brasil uma proposta de "descordialização do Brasil" e de formatação de um espaço público renovado, no seu entender, não se trata propriamente "da questão do Estado". Procuramos colocar em debate essa afirmação adiante.

Antes, porém, traçamos uma outra linha de conexão possível: a posição social de ambos os intelectuais e a sua atitude política. Parece-nos que a afirmação de Antonio Candido (I988, p. 64) sobre o pensamento "radical" de Sérgio Buarque se encaixa perfeitamente em Celso Furtado: "chamo de radical o pensamento que visa à transformação radical da sociedade num sentido de igualdade e justiça social, implicando a perda de privilégios das camadas dominantes", com a particularidade de que esse pensamento se desenvolve nos setores progressistas das classes médias, e não se assume como revolucionário "no sentido marxista estrito".

Essa veia de radicalidade encontra-se em Raízes do Brasil, não apenas nas críticas à "praga do bacharelismo", "ao amor pronunciado pelas formas fixas e pelas leis genéricas" ou às panaceias propostas pelos "pedagogos da prosperidade” (HOLANDA, [I936] 2006, p. I72; p. I82), que casam bem com o estilo literário e o comportamento republicano de Furtado.

No capítulo 7 da sua obra, o historiador paulista perscruta uma "revolução lenta, mas segura e concertada" (HOLANDA, [I936] 2006, p. I87). Um "novo sistema" se erige nos centros urbanos, assim como um novo "centro de exploração industrial" no oeste paulista, que aos poucos "deixa de ser uma baronia" (HOLANDA, [I936] 2006, p. I93). A Abolição da escravidão é uma espécie de síntese dos acontecimentos que se projetam adiante em forma estilizada.

Sem qualquer idealização, as tensões sociais e históricas mudam de patamar. Até porque, conforme a leitura de Sérgio Buarque, a República "não criou nenhum patriciado, mas apenas uma plutocracia". O antigo Estado mantém as formas exteriores do sistema tradicional. O quadro é marcado pela "separação da vida política e social". Duas saídas, igualmente enganosas, se colocam: o "liberalismo" e o "caudilhismo", incapazes de levar a uma "superação da doutrina democrática" (HOLANDA, [I936] 2006, p. I93-I98). Em síntese, se "o Estado opõe-se à ordem natural e a transcende", essa "oposição" apenas adquire sentido se tiver como "contraponto" um quadro social que lhe seja coerente" (HOLANDA, [I936] 2006, p. 208).

Conforme a síntese de Robert Wegner (2006, p. 356), "as mudanças econômicas e institucionais diluem as formas culturais tradicionais", mas sem gerar novos padrões de sociabilidade que forneçam substrato às instituições estatais. Estamos numa situação peculiar, pois nem a sociedade organizada e tampouco o Estado burocrático podem encher a cena. Ambos necessitam do suporte um do outro.

Furtado será o teórico dessa tensão criativa entre as duas esferas quando a história o permitir, ou seja, quando novos segmentos se arvorarem a classes 
dirigentes do Estado, em busca de pontos de apoio na sociedade, já parcialmente transformada pelas políticas e reformas estatais. Tensão criativa desestruturada por força das contradições internas e externas - como ele mesmo relata, em I964, no seu livro a Dialética do desenvolvimento. É quando nosso intelectual inicia um novo ciclo de interpretações do Brasil, mais profundas e multidimensionais, mais focadas no contemporâneo do que no histórico, uma vez expurgado do seu centro privilegiado de observação e ação, o Estado.

Finalmente, vale destacar que a inserção de Furtado no "campo problemático" das interpretações do Brasil se dá, não de maneira explícita, mas por meio de um esforço metodológico próprio, com o objetivo de recolocar em outro patamar a "diferença" brasileira. Seu principal ativo não reside no economista, mas na sua capacidade de, sendo-o, se projetar para além da economia a partir de categorias por ele forjadas para penetrar na dinâmica do desenvolvimento, em diversas temporalidades e espaços, realçando o papel das estruturas sociais e políticas locais/nacionais e internacionais.

O processo não é nada linear, pois cada corte transversal traz consigo novas coordenadas que interagem entre si à maneira de constelações de forças que avançam em forma de espiral até a próxima ruptura por meio da qual novo rearranjo se processa. Essa combinação gera diversos padrões de desenvolvimento, o que inclui as diferentes estruturas subdesenvolvidas que desfilam em diversos pontos do território brasileiro como num filme de longa-metragem feito de momentos de parada e aceleração. O objetivo é decupar a realidade espaçotemporal multifacetada, produto da história e que se atualiza como amplo mosaico de formas no contexto de industrialização, quando se torna possível um autêntico projeto de transformação nacional.

É então que um novo agente, o Estado, aparece como espaço potencial de resolução dos conflitos de forma democrática. Abre-se assim uma nova "sequência" de compreensão do movimento da sociedade brasileira, distinta daquela processada no período anterior. Ela não é resultado direto do "acúmulo intelectual" anterior, pois essa interpretação do Brasil origina-se do método por ele concebido para contrastar a dinâmica das estruturas econômicas e sociais com a emergência ou de centros de decisão dependentes ou potencialmente transformadores - quadro tecido a partir do fluxo histórico afunilado em um presente prenhe de oportunidades. O intelectual reposiciona assim os "velhos problemas", que aparecem por meio da perspectiva potencialmente dialética (e não necessariamente dualista) com que concebe o desenvolvimento nacional ${ }^{\mathrm{I}}$.

\section{CONSIDERAÇõES FINAIS}

Por que Celso Furtado não atualizou Formação econômica do Brasil? Sugiro uma hipótese simples e, portanto, longe de definitiva. Porque sua incursão no passado estava inscrita num projeto e numa utopia que não se confirmaram. Incorporar a sua análise para os períodos posteriores, mudando a composição do livro, significaria

Io Os termos entre aspas dos parágrafos acima representam uma tentativa de diálogo com as categorias trabalhadas por Botelho (2020, p. 26-28; p. 35-36; p. 4I-44). 
matar a força retórica e discursiva por meio da qual ele se transformou em ator do processo histórico.

Nas suas posteriores interpretações do Brasil, Formação econômica do Brasil é reescrita de várias formas, sempre acionando o método histórico-estrutural, para mostrar como a reorganização das relações centro-periferia junto com o enraizamento do subdesenvolvimento e da dependência travaram a possibilidade de construção de um sistema econômico nacional sob bases democráticas. Partindo de outro posto de observação, a universidade e o exílio, Furtado refaz as suas categorias e a sua narrativa do processo histórico, inclusive apurando seu método.

É nesse sentido que seu pensamento se revela original e ainda capaz de captar o andamento assincrônico das estruturas que conformam a realidade do "capitalismo global" e a variedade de capitalismo entronizada no país. Atualizar o seu pensamento é ser fiel ao seu método para descobrir por conta própria - como ele fazia - o movimento para além da superfície dos fatos econômicos.

Na encruzilhada em que vivemos desde 20I6, ser furtadiano não é uma questão apenas de princípio, mas de compromisso com a objetividade e a imaginação criadora para flagrar as tensões estruturais - e as linhas de ação correspondentes - que permitam novamente conjugar desenvolvimento, democracia e justiça social.

SOBRE O AUTOR

ALEXANDRE DE FREITAS BARBOSA é professor de História Econômica e Economia Brasileira do Instituto de Estudos Brasileiros da Universidade de São Paulo (IEB/USP) e bolsista Produtividade CNPq (categoria 2). afbarbosa@usp.br https://orcid.org/oooo-0oo2-0493-7488

\section{REFERÊNCIAS}

ALENCASTRO, Luiz Felipe de. Prefácio. In: FURTADO, Celso. Formação econômica do Brasil. Edição comemorativa - 50 anos. Organização de Rosa Freire d'Aguiar. São Paulo: Companhia das Letras, 2009.

BARBOSA, Alexandre de Freitas. Formação econômica do Brasil, cinquenta anos depois. Revista do Instituto de Estudos Brasileiros, n. 50, set.-mar. 20I0, p. I45-162.

BARBOSA, Alexandre de Freitas. “Developmentalist Brazil” (I945-I964) as a concept: historicizing and (re) periodizing development in Brazil). Brazilian Journal of Political Economy, v. 40, n. 2, April-June/2020, p. 332-354.

BOTELHO, André. Um certo “ar de família”: formação, inserção, linhagens, sequências. In: SAES, Ale- 
xandre Macchione; BARBOSA, Alexandre de Freitas (org.). Celso Furtado e os 60 anos de Formação econômica do Brasil. São Paulo: Editora Sesc/Publicações BBM, 202I.

BIELSCHOWSKY, Ricardo. Pensamento econômico brasileiro: o ciclo ideológico do desenvolvimentismo. 2. ed. Rio de Janeiro: Contraponto, I995.

BRAUDEL, Fernand. (1958). História e as ciências sociais: a longa duração. In: BRAUDEL, Fernand. Escritos sobre a história. 2. ed. São Paulo: Perspectiva, I992.

CANDIDO, Antonio. Sérgio Buarque de Holanda, o radical. In: NOGUEIRA, Arlinda Rocha et al. (org.) Sérgio Buarque de Holanda: vida e obra. São Paulo: Secretaria de Estado da Cultura; IEB, I988.

CARDOSO, Fernando Henrique. (I978). Celso Furtado: o descobrimento da economia. In: CARDOSO, Fernando Henrique. Pensadores que inventaram o Brasil. São Paulo: Companhia das Letras, 2013.

CEPÊDA, Vera Alves. O pensamento político de Celso Furtado: desenvolvimento e democracia. In: BRESSER-PEREIRA, Luiz Carlos; REGO, José Marcio (org.). A grande esperança em Celso Furtado: ensaios em homenagem aos seus 80 anos. São Paulo: Editora 34, 200I, p. I67-I84.

D’AGUIAR, Rosa Freire. Apresentação. In: FURTADO, Celso. Formação econômica do Brasil: edição comemorativa - 50 anos. Organização de Rosa Freire d'Aguiar Furtado. São Paulo: Companhia das Letras, 2009, p. II-2I.

DAIX, Pierre. Fernand Braudel: uma biografia. Rio de Janeiro: Record, I999.

FREYRE, Gilberto. (1933). Casa-grande e`senzala. I6 ed. Rio de Janeiro: José Olympio, I973.

FREYRE, Gilberto. (I936). Sobrados e mucambos. 9. ed. Rio de Janeiro: Record, I996.

FURTADO, Celso. A economia brasileira: contribuição à análise do seu desenvolvimento. Rio de Janeiro:

A Noite, I954.

FURTADO, Celso. A pré-revolução brasileira. Rio de Janeiro: Fundo de Cultura, I962.

FURTADO, Celso. (I96I). Desenvolvimento e subdesenvolvimento. 5. ed. Rio de Janeiro: Fundo de Cultura, I965.

FURTADO, Celso. Analyse économique et histoire quantitative. In: L'histoire quantitative du Brésil de I80o à I930. Colloques Internationaux du Centre National de la Recherche Scientifique. Paris: Centre National de la Recherche Scientifique, [II-I5 Octobre I97I], n. 543, I973, p. 23-26.

FURTADO, Celso. O mito do desenvolvimento econômico. 4. ed. Rio de Janeiro: Paz e Terra, I974.

FURTADO, Celso. A fantasia organizada. 5. ed. Rio de Janeiro: Paz e Terra, I985.

FURTADO, Celso. (I967). Teoria e política do desenvolvimento econômico. 9. ed. São Paulo: Companhia Editora Nacional, I987.

FURTADO, Celso. (I959). Formação econômica do Brasil. 23. ed. São Paulo: Companhia Editora Nacional, I989.

FURTADO, Celso. Brasil: a construção interrompida. Rio de Janeiro: Paz e Terra, I992.

FURTADO, Celso. O capitalismo global. São Paulo: Paz e Terra, I998.

FURTADO, Celso. Mensagem aos jovens economistas. In: FURTADO, Celso. O longo amanhecer: reflexões sobre a formação do Brasil. São Paulo: Paz e Terra, I999, p. 69-I02.

FURTADO, Celso. (I980). Introdução ao desenvolvimento: enfoque histórico-estrutural. 3. ed. São Paulo: Paz e Terra, 2000.

FURTADO, Celso. (I948). Economia colonial no Brasil nos séculos XVI e XVII. São Paulo: Hucitec; ABPHE, $200 I$. FURTADO, Celso. Formação econômica do Brasil: edição comemorativa - 50 anos. Organização de Rosa Freire d'Aguiar. São Paulo: Companhia das Letras, 2009.

FURTADO, Celso. (I973). Aventuras de um economista brasileiro. In: D’AGUIAR, Rosa Freire (org.). Essencial Celso Furtado. Organização, apresentação e notas de Rosa Freire d'Aguiar. São Paulo: Companhia das Letras, 20I3a.

FURTADO, Celso. (1987). Entre inconformismo e reformismo. In: D’AGUIAR, Rosa Freire (org.). Essencial 
Celso Furtado. Organização, apresentação e notas de Rosa Freire d'Aguiar. São Paulo, Companhia das Letras, 20I3b.

FURTADO, Celso. Diários intermitentes: I937-2002. Organização, apresentação e notas de Rosa Freire d’Aguiar. Prefácio de João Antonio de Paula. São Paulo: Companhia da Letras, 2019.

HOLANDA, Sérgio Buarque de. Raízes do Brasil. Edição comemorativa - 70 anos. Organização de Ricardo Benzaquen de Araújo e Lilian Moritz Schwarcz. São Paulo: Companhia das Letras, 2006.

IGLESIAS, Francisco. (I963). Prefácio à edição especial da Coleção Biblioteca Básica Brasileira - UnB. In: FURTADO, Celso. Formação econômica do Brasil. Edição comemorativa - 50 anos. Organização de Rosa Freire d'Aguiar. São Paulo: Companhia das Letras, 2009.

MALLORQUIN, Carlos. Celso Furtado: um retrato intelectual. São Paulo: Xamá; Rio de Janeiro: Contraponto, 2005.

MAURO, Frédéric. (1972). Prefácio à edição francesa. In: FURTADO, Celso. Formação econômica do Brasil. Edição comemorativa - 50 anos. Organização de Rosa Freire d'Aguiar. São Paulo: Companhia das Letras, 2009.

O LONGO amanhecer: cinebiografia de Celso Furtado. Direção de José Mariani. Rio de Janeiro, 2004. (73 min.).

OLIVEIRA, Francisco. Viagem ao olho do furacão: Celso Furtado e o desafio do pensamento autoritário brasileiro. Novos Estudos Cebrap, n. 48, julho I997, p. 3-I9. Disponível em: http://novosestudos.com. br/produto/edicao-48. Acesso em: ago. 2020.

OLIVEIRA, Francisco de. A navegação venturosa: ensaios sobre Celso Furtado. São Paulo: Boitempo, 2003.

PRADO JR., Caio. Formação do Brasil contemporâneo. São Paulo: Livraria Martins Editora, I942.

PRADO JR., Caio. Diretrizes para uma política econômica brasileira. São Paulo: Gráfica Urupês, I954.

PRADO JR., Caio. (I945). História econômica do Brasil. 32. ed. São Paulo: Brasiliense, I985.

ROMANO, Ruggiero. (I970). Prefácio à edição italiana. In: FURTADO, Celso. Formação econômica do Brasil.

Edição comemorativa - 50 anos. Organização de Rosa Freire d’Aguiar. São Paulo: Companhia das Letras, 2009.

SILVA, Roberto Pereira. O jovem Celso Furtado: história, política e economia (I94I-I948). Bauru: Edusc, 20II. SOLA, Lourdes. Ideias econômicas, decisões políticas. São Paulo: Edusp, I998.

WEGNER, Robert. Um ensaio entre o passado e o futuro. In: HOLANDA, Sérgio Buarque de. Raízes do Brasil. Edição comemorativa - 70 anos. Organização de Ricardo Benzaquen de Araújo e Lilian Moritz Schwarcz. São Paulo: Companhia das Letras, 2006. 